\title{
Isolation of Desulfomicrobium orale sp. nov. and Desulfovibrio strain NY682, oral sulfate-reducing bacteria involved in human periodontal disease
}

\author{
1 Department of Dentistry, \\ University of Nijmegen, \\ NL-6500 HB Nijmegen, \\ The Netherlands \\ 2 Institute for Preventive \\ Dentistry and Oral \\ Microbiology, Dental \\ Centre, University of Basel, \\ Basel, Switzerland \\ 3 Oral Microbiology, \\ University of \\ Witten/Herdecke, Witten, \\ Germany
}

\author{
P. S. Langendijk, ${ }^{1} \dagger$ E. M. Kulik, ${ }^{2}$ H. Sandmeier, ${ }^{2}{ }^{2}$. Meyer ${ }^{2}$ \\ and J. S. van der Hoeven ${ }^{3}$
}

\begin{abstract}
Author for correspondence: Petra S. Langendijk. Tel: +41 2270255 14. Fax: +41 227025502. e-mail: P.Langendijk@dent.kun.nl
\end{abstract}

\begin{abstract}
The species of sulfate-reducing bacteria that prevail in sites affected by periodontal disease may be different from those commonly occurring in the digestive tracts of healthy individuals. Ten strains of mesophilic sulfatereducing bacteria (SRB) were isolated from subgingival plaque in periodontal lesions of ten patients with periodontitis. Characterization on the basis of morphological, physiological and phylogenetic properties demonstrated two distinct types of oral SRB. One strain was a curved rod with high motility. For dissimilatory sulfate reduction, lactate or pyruvate was oxidized incompletely to equimolar amounts of acetate. Desulfoviridin and cytochrome $c_{3}$ were present in this mesophilic vibrio and the cellular lipid profile was similar to that from members of the genus Desulfovibrio. The $16 \mathrm{~S}$ rDNA sequence was similar to that of the proposed 'Desulfovibrio fairfieldensis'. Cells of the nine other strains were straight, rod-shaped, exhibited a low growth rate and oxidized substrates incompletely to acetate. These SRB, like members of the genus Desulfomicrobium, lacked desulfoviridin. Analysis of the 16S rDNA sequences of seven of the nine isolates showed a high degree of similarity among these oral strains, forming a distinct lineage within the genus Desulfomicrobium. The cellular lipid profile of a representative oral strain, NY678', was in accordance with that of other Desulfomicrobium species, but also showed dissimilar features. The phenotypic and phylogenetic analyses indicate that these rod-shaped SRB from the oral cavity could be regarded as a new species, for which the designation Desulfomicrobium orale sp. nov. is proposed.
\end{abstract}

Keywords: dental microbiota, sulfate-reducers, 16S rDNA analysis, cellular fatty acids, subgingival species

\section{INTRODUCTION}

The majority of adults experience gingivitis and some degree of periodontitis, inflammatory diseases that

\footnotetext{
† Present address: Département de Biochimie Médicale, Faculté de Médecine, CMU, Université de Genève, 1 rue Michel-Servet, 1211 Genève 4, Switzerland.

Abbreviation: SRB, sulfate-reducing bacteria.

The GenBank/EMBL accession numbers for the 16S rDNA sequences of strains NY678', NY676, NY677, NY679, NY683, NY682 and FD1 are AJ251623, AJ251628, AJ251629, AJ251624, AJ251627, AJ251630 and AJ251631, respectively.
}

affect the tooth-supporting tissues. In contrast to gingivitis, periodontitis involves deeper tissues and implies destruction of connective-tissue attachment and of the adjacent alveolar bone; this leads eventually to the loss of teeth. In $5-20 \%$ of adults, severely progressive forms of periodontitis cause extensive loss of tooth-supporting connective tissue and bone (Brown \& Löe, 1993). Affected sites, where a pocket is formed between the tooth and the periodontal tissue, harbour a diverse microbiota of predominantly anaerobic bacteria, in which more than 500 different bacterial species have been detected (Moore \& Moore, 1994). Certain periodontal bacteria, such as Actino- 
bacillus actinomycetemcomitans, Porphyromonas gingivalis and spirochaetes, are suspected pathogens in the complex aetiology of periodontal diseases (Haffajee \& Socransky, 1994; Socransky \& Haffajee, 1997).

Recently, sulfate-reducing bacteria (SRB) have been detected in periodontal pockets (van der Hoeven et al., 1995). SRB mineralize products of fermentation and participate as terminal degraders in the anaerobic degradation of organic matter, e.g. in marine sediments and in wastewater-purification plants (Widdel, 1988; Hansen, 1993). The accumulation of their product, $\mathrm{H}_{2} \mathrm{~S}$, is highly toxic to plants, animals and all other living cells, and may become dangerous for humans under poorly ventilated conditions (Beauchamp et al., 1984). The SRB form a heterogeneous assemblage of strictly anaerobic species that demand anoxic, reducing conditions for their growth in pure culture (Postgate, 1984). However, in mixed populations, SRB are able to grow in oxic zones of biofilms and microbial mats (Santegoeds et al., 1998; Okabe et al., 1999; Canfield \& Des Marais, 1991).

In addition, the presence of several genera of SRB (including Desulfovibrio, Desulfobacter, Desulfomonas, Desulfobulbus and Desulfotomaculum) in the guts of humans and animals has been reported (Gibson et al., 1988, 1991; Lin et al., 1997). Members of the genus Desulfovibrio are commonly found in the intestine, but a relationship between an increase in the presence of Desulfovibrio species in the human intestine and ulcerative colitis was indicated by Gibson et al. (1991).

SRB occur in the mouths of approximately $10 \%$ of healthy subjects (Langendijk et al., 1999); these bacteria could be detected on the tongue, on various oral mucosal tissues (Willis et al., 1995), in plaque and in saliva (Willis et al., 1999). Recently, the presence of oral SRB was shown to be related to several clinical categories of periodontal disease, including early-onset periodontitis, rapidly progressive periodontitis, adult periodontitis and refractory periodontitis (Langendijk et al., 2000). Among periodontitis patients, the frequency of the presence of SRB increased significantly (to $58-72 \%$ of the patients). SRB showed a strong association with adult periodontitis, as $72 \%$ of such patients harboured SRB in at least one periodontal pocket. Furthermore, the presence of SRB in periodontal sites was correlated with increased periodontal pocket depth. Accordingly, SRB could serve as risk indicators for periodontal disease (Langendijk et al., 2000).

However, certain species of SRB might have relationships to oral health or disease that differ from those of others. So far, only preliminary taxonomic identification of oral SRB has been reported. Some periodontal isolates were suggested to belong to the genera Desulfovibrio and Desulfobacter (van der Hoeven et al., 1995). Oral SRB from periodontally healthy subjects were identified as Desulfovibrio species, although they were less vibrioid and motile and grew at a particularly slow rate compared with intestinal strains (Willis et al., 1995). In comparison, samples from healthy oral mucosa required significantly longer incubation times to show sulfate-reducing activity than samples from periodontal pockets (Langendijk et al., 1999). This may be due to the presence of SRB in smaller cell numbers, but, alternatively, it might indicate that SRB from periodontal pockets possess particular physiological properties in comparison with SRB from other environments. In this study, SRB were isolated from periodontal pockets for identification and the characterization of their morphological, physiological and phylogenetic properties.

\section{METHODS}

Samples and enrichment cultures. In four dental clinics, three in the Netherlands and one in Germany, samples were taken from a total of 83 patients who were being treated for periodontitis (van der Hoeven et al., 1995; Langendijk et al., 1999, 2000). The deepest periodontal pockets were selected for sampling $(n=220)$. Supragingival plaque was removed and, after placement of cotton rolls, the site was blown dry to remove saliva. A sterile, medium-sized paper point was inserted deeply into the pocket and left for $20 \mathrm{~s}$. Immediately thereafter, the paper point was submerged into a vial with $2 \mathrm{ml}$ enrichment medium (van der Hoeven et al., 1995) and minimal headspace. Samples were transferred within $24 \mathrm{~h}$ to an anoxic chamber (MB200; Braun) with an oxygen partial pressure below 5 p.p.m. In the chamber, the headspace of the samples was replaced with $5 \% \mathrm{CO}_{2}, 4 \% \mathrm{H}_{2}$ and $91 \% \mathrm{~N}_{2}$ and the enrichment samples were incubated in this atmosphere at $35^{\circ} \mathrm{C}$ for 2 months. Strong blackening due to FeS precipitation indicated the presence of SRB.

Isolation and cultivation of strains. The enrichment medium was prepared as described previously (van der Hoeven et al., 1995). Briefly, the semi-synthetic mineral medium was supplemented with $1 \mathrm{~g}$ yeast extract $\mathrm{l}^{-1}$ and $30 \mathrm{mg}$ $\mathrm{Na}_{2} \mathrm{~S}_{2} \mathrm{O}_{4} 1^{-1}$ was added to lower the redox potential. A combination of lactate, pyruvate, acetate, propionate and citrate served as electron donors. Inorganic sulfate served as the electron acceptor and $\mathrm{FeSO}_{4}$ was the indicator for sulfate-reducing activity. Agar plates for the isolation of strains were composed of the same medium, supplemented with $20 \mathrm{~g}$ agar $1^{-1}$.

Colonies showing strong blackening due to sulfidogenic activity were streaked until purity onto agar plates. Ten isolates obtained from ten distinct patients were characterized further.

The isolated strains were finally grown on plates of enriched blood agar composed of $\left(1^{-1}\right): 25 \mathrm{~g}$ brain-heart infusion (Difco), $10 \mathrm{~g}$ bacto-peptone (Difco), $10 \%$ (v/v) defibrinated sheep blood, $23 \mathrm{mM}$ sodium lactate, $1 \mathrm{~g} \mathrm{KNO}_{3}, 1 \mathrm{~g}$ disodium succinate, $1 \mathrm{~g}$ sodium formate, $2 \mathrm{~g} \mathrm{Na}_{2} \mathrm{SO}_{4}, 0.5 \mathrm{~g}$ $\left(\mathrm{NH}_{4}\right)_{2} \mathrm{Fe}\left(\mathrm{SO}_{4}\right)_{2} \cdot 6 \mathrm{H}_{2} \mathrm{O}, 5 \mathrm{mg}$ haemin, $1 \mathrm{mg}$ vitamin $\mathrm{K}_{1}, 20 \mathrm{~g}$ bacto-agar (Difco) and $30 \mathrm{mg} \mathrm{Na} \mathrm{S}_{2} \mathrm{O}_{4}$. All incubations were at $35^{\circ} \mathrm{C}$ in the anoxic chamber. Strains were stored in $200 \mathrm{~g}$ skimmed milk $1^{-1}$ at $-80^{\circ} \mathrm{C}$. Two of the isolated strains, NY682 and NY678 ${ }^{\mathrm{T}}$, have been submitted to the Deutsche Sammlung von Mikroorganismen und Zellkulturen (DSMZ), Braunschweig, Germany, and are referred to as DSM 12803 and DSM $12838^{\mathrm{T}}$, respectively. 
Strain FD1, an intestinal isolate from a human colon, was obtained from G. R. Gibson (Cambridge, UK) and was used as a control for DNA extraction and amplification.

Physiological analyses of growth and substrates. Cell density was determined with a Shimadzu UV-160A spectrophotometer, using $1 \mathrm{~cm}$ cuvettes at $550 \mathrm{~nm}$.

Utilization of different substrates was tested in a basal medium prepared according to van der Hoeven et al. (1995). The medium contained $\left(\mathrm{l}^{-1}\right): 3.0 \mathrm{mg} \mathrm{CaCl}_{2} . \mathrm{H}_{2} \mathrm{O}, 0.65 \mathrm{~g}$ $\mathrm{K}_{2} \mathrm{HPO}_{4} .3 \mathrm{H}_{2} \mathrm{O}, 1.0 \mathrm{~g} \mathrm{NH} \mathrm{NH}_{4}, 1.65 \mathrm{~g} \mathrm{MgCl}_{2} .6 \mathrm{H}_{2} \mathrm{O}, 2.0 \mathrm{~g}$ $\mathrm{NaHCO}_{3}, 1.0 \mathrm{~g}$ yeast extract, $1.0 \mathrm{~g}$ agar, $0.8 \mathrm{mg}$ resazurin and $30 \mathrm{mg} \mathrm{Na} \mathrm{S}_{2} \mathrm{O}_{4}$. The basal medium was supplemented as indicated with $18 \mathrm{mM} \mathrm{Na} \mathrm{SO}_{4}$ and either $20 \mathrm{mM}$ sodium lactate, $20 \mathrm{mM}$ sodium pyruvate, $20 \mathrm{mM}$ disodium propionate, $10 \mathrm{mM}$ ethanol, $101 \mathrm{kPa} \mathrm{H}_{2}, 40 \mathrm{mM}$ sodium formate or $20 \mathrm{mM}$ sodium acetate, at a final $\mathrm{pH}$ of $7 \cdot 6$. To determine the growth rates of strains NY682 and NY678 ${ }^{\mathrm{T}}$, the medium was supplemented with $20 \mathrm{mM}$ sodium lactate and $20 \mathrm{mM} \mathrm{Na}_{2} \mathrm{SO}_{4}$.

After 4 weeks' incubation, the concentrations of fatty acids and sulfate were determined by capillary electrophoresis over an uncoated capillary (inner diameter, $75 \mu \mathrm{m}$; length, $40 \mathrm{~cm}$ to the detector), using the P/ACE system 2210 (Beckman). The buffer used was composed of $20 \mathrm{mM} \mathrm{L-}$ histidine and $0 \cdot 1 \mathrm{mM}$ cetyltrimethylammonium bromide; phthalic acid was used to adjust the $\mathrm{pH}$ to 5.6. Measurements were performed at reversed polarity (System Gold integration program; Beckman) at $10 \mathrm{kV}$ and $25^{\circ} \mathrm{C}$ by indirect detection at $254 \mathrm{~nm}$.

The ranges of temperature for growth of oral Desulfovibrio strain NY682 and oral Desulfomicrobium strain NY678 were determined by incubation in basal medium supplemented with $20 \mathrm{mM}$ lactate, $18 \mathrm{mM}$ sulfate and $0.5 \mathrm{~g}$ $\mathrm{FeSO}_{4} \cdot 7 \mathrm{H}_{2} \mathrm{O} \mathrm{l}^{-1}$ for 5 months (in triplicate).

Analyses of cellular components and pigments. For electronmicroscope analysis, cells were washed gently in PBS $\left(\mathrm{pH} 7 \cdot 6\right.$ ) and concentrated to an $\mathrm{OD}_{550}$ of 1 , which was determined using a Shimadzu UV-160A spectrophotometer. Aliquots were applied to a nickel Formvar-coated grid for $15 \mathrm{~min}$, blotted dry and then stained for $5 \mathrm{~s}$ with a $1 \%(\mathrm{w} / \mathrm{v})$ phosphotungstic acid solution $(\mathrm{pH} \mathrm{7 \cdot 0)}$.

The presence of desulfoviridin was determined by its red fluorescence in UV light in 300-fold concentrated cell suspensions immediately after the addition of $2 \mathrm{M} \mathrm{NaOH}$ (Postgate, 1984). Desulfomonas pigra DSM $749^{\mathrm{T}}$ or Desulfovibrio desulfuricans subsp. desulfuricans DSM 6949 served as the positive control and Desulfomicrobium escambiense DSM $10707^{\mathrm{T}}$ served as the negative control.

Cytochromes of oral Desulfovibrio strain NY682 and oral Desulfomicrobium strain NY678 ${ }^{\mathrm{T}}$ grown with $20 \mathrm{mM}$ lactate and $20 \mathrm{mM}$ sulfate were identified in dithionite-reduced versus air-oxidized cell suspensions by spectroscopy using a Shimadzu UV-160A spectrophotometer (Smith, 1978).

Cellular fatty acids were determined from cultures in lateexponential growth phase in basal medium, without agar, supplemented with $24 \mathrm{mM}$ sodium lactate and $20 \mathrm{mM}$ $\mathrm{Na}_{2} \mathrm{SO}_{4}$. Fatty acids were extracted and analysed at the DSMZ by gas chromatography as described by Vainshtein et al. (1992).
The $\mathrm{G}+\mathrm{C}$ content of the genomic DNA was determined at the DSMZ by using HPLC according to the method of Mesbah et al. (1989).

DNA extraction. Before DNA extraction, $1 \mathrm{ml}$ culture was centrifuged at $10000 \mathrm{~g}$ at $4{ }^{\circ} \mathrm{C}$ for $3 \mathrm{~min}$, resuspended and then washed in $50 \mathrm{mM}$ sodium acetate $/ 10 \mathrm{mM}$ EDTA $(\mathrm{pH}$ $5 \cdot 1)$. Lysozyme was added at a final concentration of $1 \mathrm{mg} \mathrm{ml}^{-1}$; this was followed by incubation at $37^{\circ} \mathrm{C}$ for $30 \mathrm{~min}$. Proteinase K $\left(0.5 \mathrm{mg} \mathrm{ml}^{-1}\right)$ and SDS $(0.5 \%, \mathrm{w} / \mathrm{v})$ were subsequently added and incubation was continued at $50{ }^{\circ} \mathrm{C}$ for $15 \mathrm{~min}$. Nucleic acids were then extracted by phenol/chloroform treatment and were purified by ethanol precipitation (Sambrook et al., 1989). DNA was suspended in $50 \mu \mathrm{l} 10 \mathrm{mM}$ Tris $/ \mathrm{HCl}(\mathrm{pH} 8 \cdot 0) / 1 \mathrm{mM}$ EDTA.

DNA amplification. Full-length $16 \mathrm{~S}$ rDNA was amplified from isolates NY678 ${ }^{\mathrm{T}}$ ( = DSM 12838 ${ }^{\mathrm{T}}$ ), NY682 ( = DSM 12803), NY676, NY677, NY679, NY683 and FD1, using the eubacterial primers 8f and 1492r (Lane, 1991; Relman, 1993). Amplification was performed in a Perkin Elmer thermocycler 2400 employing the hot-start technique with AmpliWax PCR Gem 100 wax beads (Perkin Elmer). The lower phase ( $25 \mu 1$ volume) contained PCR buffer L [final concentrations: $10 \mathrm{mM}$ Tris $/ \mathrm{HCl}, \mathrm{pH} 8.85 ; 5 \mathrm{mM}$ $\left(\mathrm{NH}_{4}\right)_{2} \mathrm{SO}_{4} ; 3 \mathrm{mM} \mathrm{MgSO}$ ], primers at $0.3 \mu \mathrm{M}$ each and $10 \mu \mathrm{l}$ template DNA. The upper phase $(75 \mu \mathrm{l}$ volume $)$ contained PCR buffer $U$ [final concentrations: $10 \mathrm{mM}$ Tris $/ \mathrm{HCl}, \mathrm{pH} 8.85 ; 5 \mathrm{mM}\left(\mathrm{NH}_{4}\right)_{2} \mathrm{SO}_{4} ; 3 \mathrm{mM} \mathrm{MgSO}_{4}$; $25 \mathrm{mM} \mathrm{KCl}$, dNTPs at $0.3 \mathrm{mM}$ each and $2 \mathrm{U} P$ wo DNA polymerase. The temperature profile was as follows: prePCR denaturation at $95^{\circ} \mathrm{C}$ for $2 \mathrm{~min}, 35$ cycles of denaturation at $95^{\circ} \mathrm{C}$ for $15 \mathrm{~s}$, annealing at $63{ }^{\circ} \mathrm{C}$ for $1 \mathrm{~min}$ and extension at $72^{\circ} \mathrm{C}$ for $15 \mathrm{~s}$ and post-PCR extension at $72{ }^{\circ} \mathrm{C}$ for $7 \mathrm{~min}$. One microlitre of each of the obtained PCR products was reamplified under the same conditions for another 30 cycles. After electrophoresis, the PCR products were excised from the gel and the DNA was subsequently extracted (QIAEX kit; Qiagen). These PCR products were either cloned or $1 / 20$ of the volume was reamplified for 30 cycles under the conditions described above and subsequently cloned.

$16 S$ rDNA sequencing. Purified PCR products (PCR purification kit; Qiagen) were ligated into the SmaI site of pBluescript II SK $(-)$ and used to transform Escherichia coli XL1-Blue MRF' by electroporation. Plasmid DNA was extracted from $E$. coli transformants by alkaline lysis and was further purified on QIAGEN-tip 20 columns for sequencing with AmpliTaq FS (Perkin Elmer). Primers binding at conserved sites within the 16S rDNA were used, as well as T3 and T7 primers, and the sequencing reactions were electrophoresed on an ABI 373 automated sequencer (Perkin Elmer).

16S rDNA analysis. The 16S rDNA sequences of this study, as well as that of 'Desulfomicrobium hypogeium', were manually aligned against representative members of the $\delta$ subdivision of the Proteobacteria (Maidak et al., 1999). The sequence data of 1153 aligned bases, between Escherichia coli positions 83 and 1365, were used for the phylogenetic analysis. Phylogenetic analysis was done with a beta version of PAUP* 4.0 run on a PowerMacintosh (Swofford, 1998). Similarity matrices were corrected for multiple base changes by the method of Jukes \& Cantor (1969). Phylogenetic trees were constructed by employing the neighbour-joining method. The topology of this tree obtained after 1000 bootstraps was compared with the topologies of other trees 
after 1000 bootstraps of branch-and-bound searches using the maximum-parsimony criterion, as well as after 1000 bootstraps of heuristic searches with the maximum-likelihood criterion.

\section{RESULTS AND DISCUSSION}

\section{Isolation and morphology of oral SRB}

In $49 \%$ of the patients, SRB were present in at least one of the periodontal sites. SRB were present in $37 \%$ of the periodontal pockets that were sampled, i.e. in 138 enrichment cultures. However, few of these enrichments of SRB allowed isolation of oral strains of SRB. Agar plates showed complete blackening due to sulfide production, but sulfidogenic colonies were formed only sporadically in the absence of other oral bacteria. Ten isolates were obtained from periodontal pockets of ten different patients; one of the patients attended a German dental clinic and the other patients attended three different Dutch dental clinics for periodontal treatment (Table 1).

Nine of the isolates demonstrated highly similar morphological and physiological properties. Growth on agar plates showed complete blackening by FeS due to sulfate-reducing activity, but only tiny colonies were formed, and a binocular microscope had to be used in the anoxic chamber for routine transfer of colonies. Similarly poor growth occurred in liquid culture, as each of the nine strains showed obvious sulfide production after several days but never grew into turbid cultures. Phase-contrast microscopy of these strains revealed rod-shaped bacteria; motility was rarely observed. Electron-microscope analysis of negatively stained cells of strain $\mathrm{NY} 678^{\mathrm{T}}$ showed the presence of single polar flagella (Fig. 1). The rods were $0.6-0.8 \mu \mathrm{m}$ by $1.8-3.0 \mu \mathrm{m}$ in size.

In contrast, one of the ten isolates, strain NY682, grew much faster and showed normal colony size and turbidity in liquid cultures. Phase-contrast microscopy

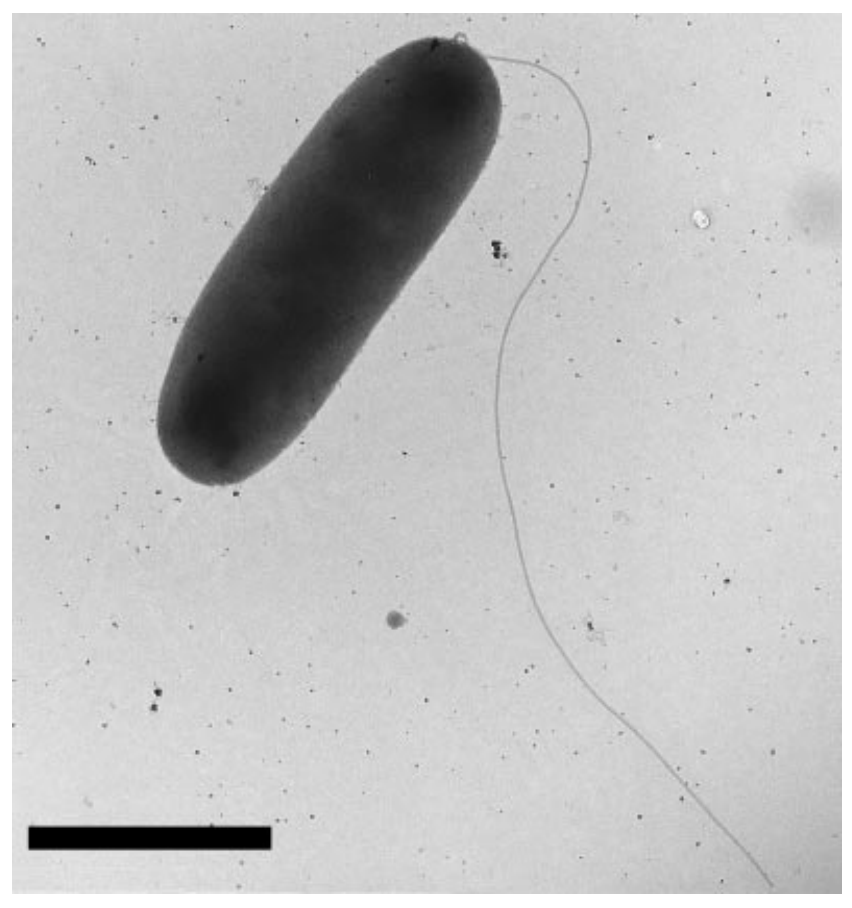

Fig. 1. Transmission electron micrograph of a negatively stained cell of Desulfomicrobium orale sp. nov., periodontal strain $\mathrm{NY} 678^{\top}$ ( = DSM $12838^{\top}$ ). Bar, $1 \mu \mathrm{m}$.

of this strain revealed curved rods. The vibrioid cells were highly motile. All of the strains were Gramnegative by staining and no spores were observed.

\section{Substrate utilization and growth}

The ten strains isolated oxidized lactate incompletely in the presence of sulfate. Equimolar amounts of acetate accumulated, which could not be utilized in a dissimilatory manner for growth (Table 1). None of the strains utilized propionate. These properties, in

Table 1. Features of sulfate-reducing bacteria (SRB) isolated from subgingival plaques of ten patients with periodontitis

Growth is scored as: - , no growth; + , low growth rate with low final OD; +++ , normal growth and turbidity; NT, not tested. All strains showed incomplete oxidation of lactate resulting in equimolar accumulation of acetate.

\begin{tabular}{|c|c|c|c|c|c|c|c|c|c|c|}
\hline Feature & $\operatorname{NY678}^{\mathrm{T}}(=$ DSM 12838 $)$ & NY684 & NY679 & NY680 & NY681 & NY683 & NY676 & NY685 & NY682 (= DSM 12803) & NY677 \\
\hline Origin of isolate* & A & $\mathrm{B}$ & $\mathrm{D}$ & G & $\mathrm{H}$ & $\mathrm{L}$ & M & $\mathrm{S}$ & $\mathrm{V}$ & W \\
\hline Morphology & Rod & Rod & Rod & Rod & Rod & Rod & Rod & Rod & Vibrio; motile & Rod \\
\hline \multicolumn{11}{|l|}{ Growth on: } \\
\hline Acetate $+\mathrm{SO}_{4}^{2-}$ & - & NT & - & - & - & NT & - & NT & - & - \\
\hline Lactate $+\mathrm{SO}_{4}^{2-}$ & + & + & + & + & + & + & + & + & +++ & + \\
\hline Propionate $+\mathrm{SO}_{4}^{2-}$ & - & NT & - & - & - & NT & NT & NT & - & - \\
\hline Presence of desulfoviridin & - & - & - & - & - & - & - & - & + & - \\
\hline Clustering of $16 \mathrm{~S}$ rDNA $\dagger$ & Dm & NT & $\mathrm{Dm}$ & $\mathrm{Dm}(\mathrm{p})$ & $\operatorname{Dm}(p)$ & $\mathrm{Dm}$ & Dm & NT & Dv & $\mathrm{Dm}$ \\
\hline
\end{tabular}

* Isolates were obtained from periodontal pockets of the patient shown. Patient $\mathrm{G}$ attended a German periodontal clinic; the other subjects were patients of three different Dutch dental clinics.

$\dagger$ Complete 16S rRNA sequences clustered within those of Desulfomicrobium spp. (Dm) or Desulfovibrio spp. (Dv); (p), partial sequences. 
Table 2. Characteristics of two representative strains of oral SRB

The two strains were selected from the strains listed in Table 1. Both strains contained cytochrome $c_{3}$ and both were positive for growth on $\mathrm{H}_{2} / \mathrm{CO}_{2}+\mathrm{SO}_{4}^{2-}$, formate $+\mathrm{SO}_{4}^{2-}$, ethanol $+\mathrm{SO}_{4}^{2-}$, pyruvate $+\mathrm{SO}_{4}^{2-}$ (consumption resulted in accumulation of equimolar amounts of acetate) and pyruvate without $\mathrm{SO}_{4}^{2-}$.

\begin{tabular}{|lcc|}
\hline Characteristic & $\begin{array}{c}\text { Desulfovibrio strain } \\
\text { NY682 (= DSM 12803) }\end{array}$ & $\begin{array}{c}\text { Desulfomicrobium orale } \\
\text { NY678 }^{\mathrm{T}}(=\mathbf{D S M ~ 1 2 8 3 8})\end{array}$ \\
\hline Cell shape & Vibrio & Rod \\
Motility & + & $+/-$ \\
Optimum temperature (range) $\left({ }^{\circ} \mathrm{C}\right)$ & $37(18-41)$ & $37(25-39)$ \\
Presence of desulfoviridin & + & - \\
G + C content of DNA $(\mathrm{mol} \%)^{*}$ & $61 \cdot 1$ & $59 \cdot 7$ \\
\hline
\end{tabular}

* The error of triplicate determinations was $0.5 \mathrm{~mol} \%$.

combination with the mesophilic temperature optimum, indicate that all of the oral strains isolated belong to the proposed family 'Desulfovibrionaceae' (Devereux et al., 1990). The substrate utilization of two representative strains is given in Tables 1 and 2.

In medium with $20 \mathrm{mM}$ lactate and $20 \mathrm{mM}$ sulfate, the rod-shaped bacteria of strain NY678 ${ }^{\mathrm{T}}$ grew for $24 \mathrm{~h}$ with a minimal doubling time of $11 \mathrm{~h}\left(\mu_{\max }=\right.$ $0.062 \mathrm{~h}^{-1}$ ) until an $\mathrm{OD}_{550}$ of 0.028 was reached. During the subsequent $27-99 \mathrm{~h}$ after inoculation, growth with a doubling time of $20 \mathrm{~h}$ could be observed, with a final $\mathrm{OD}_{550}$ of $0 \cdot 34$.

The vibrioid strain NY682 grew in the same medium at a minimal doubling time of $6 \mathrm{~h}\left(\mu_{\max }=0 \cdot 11 \mathrm{~h}^{-1}\right)$ to an $\mathrm{OD}_{550}$ of 0.18 after $24 \mathrm{~h}$. From $20-38 \mathrm{~h}$ after inoculation, the growth rate decreased to a doubling time of $8.5 \mathrm{~h}$, giving an $\mathrm{OD}_{550}$ of 0.59 after $38 \mathrm{~h}$. The molar amounts of lactate used per mole sulfate were 2.5 and 2.1 for NY678 ${ }^{\mathrm{T}}$ and NY682, respectively. The yields of strain $\mathrm{NY} 678^{\mathrm{T}}$ were $2.6 \mathrm{~g}$ cell dry mass per mole sulfate consumed and $1 \cdot 1 \mathrm{~g}$ cell dry mass per mole lactate consumed. The yields of strain NY682 were $13 \cdot 2 \mathrm{~g}$ cell dry mass per mole sulfate consumed and $6 \cdot 3 \mathrm{~g}$ cell dry mass per mole lactate consumed.

Strain NY678 ${ }^{\mathrm{T}}$ grew at temperatures from 25 to $39^{\circ} \mathrm{C}$, with an optimum growth rate at $37^{\circ} \mathrm{C}$. No growth was observed at 22 or $41^{\circ} \mathrm{C}$. Strain NY682 showed a temperature range for growth of $18-41^{\circ} \mathrm{C}$. This strain showed an optimum growth rate at $37^{\circ} \mathrm{C}$; no growth was observed at $45^{\circ} \mathrm{C}$ (Table 2).

\section{Chemotaxonomic cellular components}

Desulfoviridin was detectable in cell lysates of strain NY682, whereas the nine other strains lacked desulfoviridin (Table 1). Strains in the latter group share the non-curved morphology and the absence of desulfoviridin with members of the genus Desulfomicrobium. This genus is metabolically similar to Desulfovibrio, but is characterized by its rod-shaped morphology and by the possession of bisulfite reductase desulforubidin instead of desulfoviridin (Rozanova et al., 1988; Lee et al., 1973).

The absorption spectra of reduced versus oxidized cell suspensions of strains NY682 and NY678 ${ }^{\mathrm{T}}$ showed maxima at 552, 522 and $419 \mathrm{~nm}$. These spectral peaks correspond to the $\alpha, \beta$ and $\gamma$ peaks of cytochrome $c_{3}$ (Smith, 1978). The $\mathrm{G}+\mathrm{C}$ contents of genomic DNA of strains NY682 and NY678 ${ }^{\mathrm{T}}$ were $61 \cdot 1 \pm 0.5$ and $59 \cdot 7 \pm 0.5 \mathrm{~mol} \%$, respectively (Table 2 ).

The cellular lipid profiles of strains NY682 and NY678 ${ }^{\mathrm{T}}$ (Table 3) showed the presence of substantial proportions of isoheptadecenoate (i17:1), which is a chemotaxonomic marker of the 'Desulfovibrionaceae' (Taylor \& Parkes, 1983; Edlund et al., 1985; Tourova et al., 1998). Most of the cellular fatty acids of strain NY682 also occurred in Desulfovibrio desulfuricans strains, and were within the range of variation observed among various strains grown with either pyruvate (Vainshtein et al., 1992), $\mathrm{H}_{2} / \mathrm{CO}_{2}$ (Taylor \& Parkes, 1983) or lactate (Taylor \& Parkes, 1983; Kohring et al., 1994; Dzierzewicz et al., 1996) as the electron donor. The ratio of saturated to unsaturated fatty acids was high, as has been observed for human intestinal strains in comparison with strains of Desulfovibrio desulfuricans isolated from soil (Dzierzewicz et al., 1996). However, the content of isoheptadecenoate (i17:1) was distinctively lower in the oral vibrio NY682, and the levels of dimethyl hexadecanal (16:0 dma), cyclopropyl heptadecanoate (17:0 cyc) and hexadecanal (16:0 aldehyde) were elevated in comparison with the amounts of these fatty acids detected in strains of Desulfovibrio desulfuricans from the gut and other environments.

For strain NY678 ${ }^{\mathrm{T}}$, the major cellular fatty acids were palmitate (16:0) and stearate $(18: 0)$, as for other Desulfomicrobium spp. grown with lactate (Tourova et al., 1998). Pyruvate as a substitute for lactate resulted 
Table 3. Cellular fatty acid composition of Desulfovibrio and Desulfomicrobium species

Values are percentages of total fatty acid content. Taxa are identified as: 1, oral Desulfovibrio strain NY682; 2, Desulfovibrio desulfuricans; 3, oral Desulfomicrobium strain NY678 ${ }^{\mathrm{T}}$; 4, Desulfomicrobium baculatum; 5, Desulfomicrobium apsheronum; and 6, Desulfomicrobium norvegicum. Cumulative data for Desulfovibrio desulfuricans (five strains), Desulfomicrobium baculatum (four strains), Desulfomicrobium apsheronum DSM 5918 ${ }^{\mathrm{T}}$ and Desulfomicrobium norvegicum DSM $1741^{\mathrm{T}}$ were obtained from Taylor \& Parkes (1983), Vainshtein et al. (1992), Kohring et al. (1994), Dzierzewicz et al. (1996) and Tourova et al. (1998). Data for oral Desulfovibrio strain NY682 and oral Desulfomicrobium strain NY678 ${ }^{\mathrm{T}}$ are from this work. Potential chemotaxonomic markers are shown in italics and discriminating fatty acids are shown in bold. Abbreviations: i, iso-branched; a, anteiso-branched; alde, aldehyde; c, cis; cyc, cyclopropyl; dma, dimethylacetal; F, H, different positions of double bonds; OH, hydroxy; ECL, equivalent chain length. Fatty acids occurring in trace amounts $(<0.5 \%$ in all strains) were omitted.

\begin{tabular}{|c|c|c|c|c|c|c|c|}
\hline Fatty acid & ECL & 1 & 2 & 3 & 4 & 5 & 6 \\
\hline $12: 0$ & $12 \cdot 00$ & & $0-3 \cdot 1$ & & $0-0 \cdot 4$ & $0-1.9$ & \\
\hline $13: 0$ & $13 \cdot 00$ & & $0-0 \cdot 4$ & & & & $1 \cdot 8$ \\
\hline $14: 0$ & $14 \cdot 00$ & $2 \cdot 3$ & $0-3 \cdot 2$ & $0 \cdot 9$ & $0-2 \cdot 9$ & $0 \cdot 3-8 \cdot 0$ & \\
\hline i15: 1 & $14 \cdot 41$ & & $0-2 \cdot 9$ & & $1 \cdot 5-4 \cdot 0$ & $0-2 \cdot 4$ & $3 \cdot 6$ \\
\hline i15:0 & $14 \cdot 62$ & $21 \cdot 2$ & $1 \cdot 6-33 \cdot 1$ & $12 \cdot 4$ & $4 \cdot 7-11 \cdot 6$ & $3 \cdot 0-7 \cdot 1$ & $11 \cdot 6$ \\
\hline a $15: 0$ & $14 \cdot 71$ & $3 \cdot 4$ & $0 \cdot 6-7 \cdot 0$ & $5 \cdot 6$ & $3 \cdot 5-7 \cdot 7$ & $2 \cdot 0-4 \cdot 7$ & 7 \\
\hline $16: 0$ alde & 14.95 & $4 \cdot 5$ & $0-1 \cdot 0$ & & & & \\
\hline $15: 0$ & $15 \cdot 00$ & & $0-1 \cdot 6$ & $0 \cdot 6$ & $0-0 \cdot 8$ & $0-3 \cdot 7$ & \\
\hline $\mathrm{i} 15: 0 \mathrm{dma}$ & $15 \cdot 11$ & $0 \cdot 7$ & $0-1 \cdot 9$ & & & & \\
\hline i16: $1 \mathrm{~F}$ & $15 \cdot 41$ & & $0-1 \cdot 0$ & & $0-0.9$ & $0-1 \cdot 0$ & \\
\hline i16: $1 \mathrm{H}$ & $15 \cdot 46$ & $0 \cdot 3$ & $0-1 \cdot 4$ & & $0-2 \cdot 1$ & $0-2 \cdot 8$ & $0 \cdot 9$ \\
\hline $15: 0 \mathrm{dma}$ & $15 \cdot 49$ & & & $1 \cdot 3$ & $0-1 \cdot 2$ & & \\
\hline i16:0 & $15 \cdot 63$ & $0 \cdot 4$ & $0 \cdot 2-3 \cdot 6$ & $1 \cdot 0$ & $0-1 \cdot 0$ & $0-1 \cdot 3$ & \\
\hline $16: 1 c 9$ & $15 \cdot 82$ & $2 \cdot 1$ & $1 \cdot 3-13 \cdot 8$ & $6 \cdot 7$ & $2 \cdot 2-9 \cdot 4$ & $6 \cdot 2-8 \cdot 3$ & $2 \cdot 4$ \\
\hline $16: 1 c 11$ & $15 \cdot 91$ & & & $0 \cdot 8$ & & $0-0 \cdot 4$ & \\
\hline $16: 0$ & $16 \cdot 00$ & $27 \cdot 8$ & $3 \cdot 3-19 \cdot 7$ & $18 \cdot 8$ & $3 \cdot 6-15 \cdot 7$ & $4 \cdot 3-42$ & $2 \cdot 4$ \\
\hline i15:0 3-OH & $16 \cdot 13$ & & $0-0.5$ & 1.9 & $1 \cdot 2-2 \cdot 4$ & $0 \cdot 2-1 \cdot 8$ & $3 \cdot 8$ \\
\hline a15:0 3-OH & $16 \cdot 23$ & & & $0 \cdot 5$ & $0-1 \cdot 2$ & $0-0 \cdot 7$ & $1 \cdot 7$ \\
\hline $16: 1 c 9 \mathrm{dma}$ & $16 \cdot 29$ & $0 \cdot 8$ & & & & & \\
\hline i17: 1 & $16 \cdot 42$ & $8 \cdot 2$ & $20 \cdot 9-40 \cdot 7$ & $6 \cdot 7$ & $4 \cdot 0-28 \cdot 6$ & $1 \cdot 3-17 \cdot 8$ & $28 \cdot 8$ \\
\hline $16: 0 \mathrm{dma}$ & $16 \cdot 47$ & 6.9 & $0-1 \cdot 4$ & & $0-0 \cdot 6$ & $0-0 \cdot 3$ & $0 \cdot 6$ \\
\hline a $17: 1$ & $16 \cdot 53$ & $0 \cdot 4$ & $0-13.8$ & $1 \cdot 8$ & $0-4 \cdot 1$ & $0-2 \cdot 6$ & $4 \cdot 1$ \\
\hline i17:0 & $16 \cdot 63$ & $5 \cdot 5$ & $7 \cdot 0-15 \cdot 5$ & $3 \cdot 2$ & $0 \cdot 9-6 \cdot 9$ & $1 \cdot 2-3 \cdot 6$ & $6 \cdot 3$ \\
\hline a17:0 & $16 \cdot 72$ & $0 \cdot 4$ & $0 \cdot 5-16 \cdot 1$ & $2 \cdot 3$ & $2 \cdot 0-8 \cdot 3$ & $1 \cdot 7-4 \cdot 1$ & $6 \cdot 7$ \\
\hline $17: 1 c 9$ & $16 \cdot 79$ & & & $1 \cdot 1$ & & $0-0 \cdot 4$ & \\
\hline $17: 1 c 11$ & $16 \cdot 86$ & & $0-0 \cdot 7$ & $1 \cdot 2$ & & $0-0 \cdot 2$ & \\
\hline 17:0 cyclo & $16 \cdot 89$ & $4 \cdot 8$ & & & & & \\
\hline $17: 0$ & $17 \cdot 00$ & $0 \cdot 7$ & $0-1 \cdot 0$ & $3 \cdot 7$ & $0 \cdot 2-0 \cdot 9$ & $0.4-1 \cdot 9$ & \\
\hline $\mathrm{i} 17: 0 \mathrm{dma}$ & $17 \cdot 10$ & $1 \cdot 3$ & $0-2 \cdot 3$ & & & & \\
\hline $16: 03-\mathrm{OH}$ & $17 \cdot 52$ & & $0-0 \cdot 1$ & $1 \cdot 7$ & $0-0 \cdot 9$ & $0-0 \cdot 8$ & $0 \cdot 4$ \\
\hline $18: 1 c 9$ & $17 \cdot 77$ & $0 \cdot 5$ & $0-1 \cdot 0$ & $2 \cdot 4$ & $2 \cdot 6-6 \cdot 3$ & $2 \cdot 4-6 \cdot 3$ & $2 \cdot 2$ \\
\hline $18: 1 c 11$ & $17 \cdot 82$ & $0 \cdot 3$ & $0-2 \cdot 4$ & $7 \cdot 9$ & $6 \cdot 4-14 \cdot 2$ & $1 \cdot 0-17 \cdot 6$ & $5 \cdot 9$ \\
\hline $18: 0$ & $18 \cdot 00$ & $1 \cdot 6$ & $0 \cdot 3-6 \cdot 5$ & $16 \cdot 8$ & $6 \cdot 0-22 \cdot 8$ & $9 \cdot 0-19 \cdot 2$ & $2 \cdot 7$ \\
\hline i17:0 3-OH & $18 \cdot 16$ & & $0-3 \cdot 5$ & & $0-2 \cdot 2$ & $0-0.7$ & $2 \cdot 2$ \\
\hline $18: 0 \mathrm{dma}$ & $18 \cdot 46$ & $0 \cdot 5$ & & & $0-0 \cdot 8$ & $0-0 \cdot 8$ & \\
\hline $18: 03-\mathrm{OH}$ & $19 \cdot 55$ & & & $0 \cdot 8$ & $0-0.9$ & & $0 \cdot 3$ \\
\hline $20: 0$ & $20 \cdot 00$ & & & & $0-0 \cdot 4$ & $0-1 \cdot 1$ & \\
\hline Sum identified & & $94 \cdot 6$ & & $100 \cdot 0$ & & & \\
\hline
\end{tabular}

in a shift of $5-6 \%$ in most major fatty acids of Desulfovibrio giganteus (Vainshtein et al., 1992), and may partially account for the variation in the fatty acid profiles of Desulfomicrobium baculatum and Desulfomicrobium apsheronum reported by Vainshtein et al. (1992) and Tourova et al. (1998). The minor quantity of isoheptadecenoate (i17:1) and the prevalence of oleate $(18: 1)$ in strain $\mathrm{NY} 678^{\mathrm{T}}$ are also within the range of fatty acid profiles of other Desulfomicrobium species. Although the dominating fatty acids confirm an affiliation with the genus Desulfomicrobium, four cellular fatty acids distinguish strain $\mathrm{NY} 678^{\mathrm{T}}$ from other members of this genus. These fatty acids are heptadecanoate (17:0), two heptadecenoates (17:1c9 


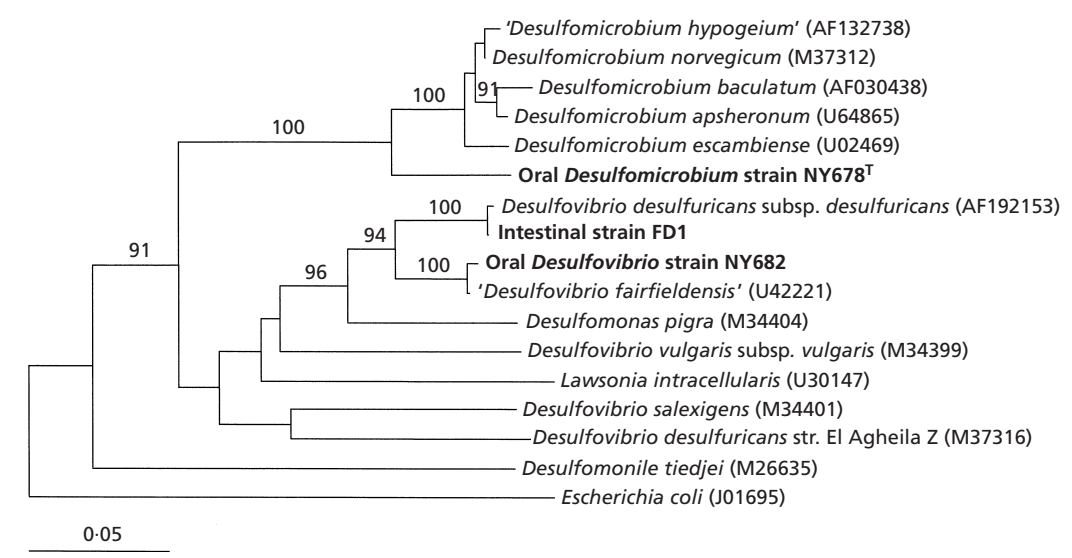

Fig. 2. Dendrogram based on $16 \mathrm{~S}$ rDNA sequences, showing the phylogenetic positions of oral SRB strains NY678 ${ }^{\top}$ (= DSM $12838^{\top}$ ) and NY682 (= DSM 12803) and the intestinal SRB strain FD1 in relation to other members of the $\delta$-subclass of the Proteobacteria. Strains from this study are shown in bold. Bootstrap values greater than $90 \%$ are shown. Bar, 5 nucleotide differences per 100 nucleotide positions.

and $17: 1 c 11)$ and 3-hydroxy palmitate $(16: 03-\mathrm{OH})$, which together amount to $7.7 \%$ of the total cellular fatty acid content of strain NY678 ${ }^{\mathrm{T}}$.

\section{Phylogenetic analysis}

The complete 16S rRNA gene sequences were determined of six of the ten oral SRB isolates. For two of the other isolates, partial 16S rDNA sequences of 400-800 bp were obtained (data not shown). The phylogenetic relationships of strains NY678 ${ }^{\mathrm{T}}$, NY682 and FD1 derived from 16S rDNA sequence analysis are depicted in Fig. 2. The 16S rDNA data showed that these strains are all members of the $\delta$-subclass of the Proteobacteria.

In the Ribosomal Database Project (RDP) database, 'Desulfovibrio fairfieldensis' was the closest relative of strain NY682 (99.7\% sequence similarity), whereas Desulfovibrio desulfuricans subsp. desulfuricans ATCC 27774 was the closest relative of the intestinal strain FD1, isolated from a human colon $(99.8 \%$ sequence similarity). The oral isolate NY682 and the colonic isolate FD1 had a sequence similarity of $96.5 \%$.

The 16S rDNA sequences of the five other strains, as well as those of the isolates that were only partially sequenced, were almost identical to each other (sequence similarities between 99.5 and $100 \%$ ). The representative strain, $\mathrm{NY} 678^{\mathrm{T}}$, was most closely related to clone Aspo1, having a sequence similarity of $95.2 \%$ (Pedersen et al., 1996). Strain NY678 ${ }^{\mathrm{T}}$ showed low sequence similarity to SRB isolated from other human sources, e.g. faeces. Even though strain NY678 ${ }^{\mathrm{T}}$ grouped with members of the genus Desulfomicrobium, the sequence similarity to $16 \mathrm{~S}$ rDNA of other Desulfomicrobium species was below $96 \%$, indicating that these oral strains may form a lineage distinct from related Desulfomicrobium species. Bootstrap analysis supported the formation of a distinct species of these oral isolates within the genus Desulfomicrobium (Fig. 2).

A number of sequence variants were observed among the oral Desulfomicrobium strains. Most of these variants might be attributable to nucleotide misincorporations during the PCR, as the sequence variations were usually found in only one of the isolated strains. However, at two positions, the oral Desulfomicrobium strains displayed a certain degree of nucleotide flexibility. In all of the members of the Desulfomicrobium baculatum subgroup present in the RDP, a guanine is found at E. coli position 455, whereas in the oral Desulfomicrobium isolates, three strains showed a guanine and two showed adenine at this position. The same applied for $E$. coli position 1291, where two of the oral strains had an adenine and three had a cytosine, the residue found in the other members of the Desulfomicrobium baculatum subgroup.

\section{Desulfomicrobium strains from oral and natural habitats}

The SRB that were isolated from the oral cavities of nine different patients from separate dental clinics were very similar and might be assignable to a single species. One strain, NY678 ${ }^{\mathrm{T}}$, was chosen as a representative of this group. The closest relatives of the nine rod-shaped oral strains are members of the genus Desulfomicrobium, which are found in various ecological habitats. Desulfomicrobium norvegicum, originally Desulfovibrio desulfuricans Norway 4, was isolated from harbour water in Oslo, Norway (Sharak Genthner et al., 1997). Strains of Desulfomicrobium baculatum, formerly named Desulfovibrio baculatus, have been isolated from manganese ore in the Russian Federation (Rozanova \& Nazina, 1976), from a forest pond (Biebl \& Pfennig, 1977) and from estuarine sediments (Laanbroek \& Pfennig, 1981) in Germany and in The Netherlands. Desulfomicrobium apsheronum was obtained from the water of an oil-bearing deposit in the Russian Federation (Rozanova et al., 1988) and Desulfomicrobium escambiense was obtained from aquatic sediment in Florida, USA (Sharak Genthner et al., 1994). Recently, a new species from $>$ 200-m-deep sandstone in New Mexico, USA, was described ('Desulfomicrobium hypogeium'; Krumholz et al., 1999). Whilst diverse Desulfomicrobium strains 
have been encountered in several parts of the world, their presence in humans has not been described previously. Our phenotypic and phylogenetic analyses indicate that these rod-shaped SRB from the oral cavity could be regarded as a distinct species, for which we propose the name Desulfomicrobium orale sp. nov.

We expect sulfate to be the growth-limiting substrate for SRB in the oral cavity (van der Hoeven et al., 1995). Under sulfate-limiting conditions, Desulfomicrobium baculatum was more competitive than Desulfobulbus and Desulfobacter species (Laanbroek et al., 1984). The low growth rate of the oral Desulfomicrobium strains observed in batch cultures might be due to direct inhibition by sulfide, iron limitation by precipitation with sulfide and/or syntrophic, interdependent growth with other bacteria.

\section{Clinical associations of Desulfovibrio strain NY682}

The morphological, physiological and phylogenetic properties of periodontal strain NY682 corresponded to those of the genus Desulfovibrio. The presence of bacteria of this genus in the mouth has been reported previously (van der Hoeven et al., 1995; Willis et al., 1995). However, the cellular lipid profile differed from that of Desulfovibrio desulfuricans strains from intestinal and other environments and the 16S rDNA showed a high degree of similarity to that of the proposed 'Desulfovibrio fairfieldensis'. Therefore, strain NY682 is identified as a member of the proposed species 'Desulfovibrio fairfieldensis'. This species has been described only partially since its recent identification, but it is of particular interest because all strains of 'Desulfovibrio fairfieldensis' have been obtained from sites of human infection. Strains of 'Desulfovibrio fairfieldensis' originate from a pyogenic liver abscess (Tee et al., 1996) and have also been detected in blood (McDougall et al., 1997; Loubinoux et al., 2000) and urine (La Scola \& Raoult, 1999). Furthermore, Loubinoux et al. (2000) isolated 'Desulfovibrio fairfieldensis' strains from blood and from abdominal abscesses of three other patients with mixed infections. Four different Desulfovibrio desulfuricans strains were isolated from a brain abscess, an appendicular abscess, an abdominal wall abscess and from blood of another three patients. Therefore, it was suggested that 'Desulfovibrio fairfieldensis' might be a potential human pathogen. However, the proposed species 'Desulfovibrio fairfieldensis' has not yet been fully characterized, and most of its physiological properties appear to be similar to those of Desulfovibrio desulfuricans.

Since many of the oral SRB grown in enrichment cultures failed to grow in pure culture, the diversity among SRB occurring in the mouth may be considerably larger than that which we observed by cultivation. Preliminary results indicated that SRB isolated from healthy oral sites were morphologically and physiologically similar to the periodontal strains (our unpublished results). Because $10 \%$ of perio- dontally healthy subjects harbour SRB in the mouth (Langendijk et al., 1999), it would be interesting to compare the SRB from healthy sites with strains from progressive periodontal pockets. As the presence of SRB appears to be related to the state of periodontal disease, there is clinical interest in identifying which of the species might be involved in destruction of periodontal tissue. Further study of the diversity of oral SRB may refine our understanding of the roles of these bacteria in oral health and disease.

\section{Description of Desulfomicrobium orale sp. nov.}

Desulfomicrobium orale (o.ra'le. L. gen. n. orale of the mouth).

Gram-negative, rod-shaped bacteria that are $0 \cdot 6-0 \cdot 8 \mu \mathrm{m}$ wide and $1 \cdot 8-3 \cdot 0 \mu \mathrm{m}$ long. Motile by a single polar flagellum. Non-spore-forming, sulfatereducing obligate anaerobe. Uses lactate, pyruvate, hydrogen, ethanol and formate as electron donors for sulfate reduction, but not acetate or propionate. Oxidizes lactate and pyruvate incompletely to acetate. Pyruvate is poorly fermented. Contains cytochrome $c_{3}$, but desulfoviridin is not detected. The temperature range for growth is $25-39^{\circ} \mathrm{C}$ (optimum $37^{\circ} \mathrm{C}$ ). The $\mathrm{G}+\mathrm{C}$ content of the genomic DNA is $59 \cdot 7 \pm 0.5 \mathrm{~mol} \%$. Habitat: human oral cavity. The type strain, NY678 ( = DSM $\left.12838^{\mathrm{T}}\right)$, was isolated from subgingival plaque of a patient with periodontitis.

\section{ACKNOWLEDGEMENTS}

We gratefully acknowledge Heinz Renggli, Wolf Grimm and Joost Hanssen for the examination of, and sampling from, patients. Furthermore, we thank G.R. Gibson for the intestinal strain, R. Kroppenstedt for fatty acid analysis, Karin Hinni for technical assistance and Pierre Genevaux for electron microscopy. Work done at the University of Basel was supported by the Swiss National Science Foundation (grant no. 32-39441.93 to J.M.).

\section{REFERENCES}

Beauchamp, R. O., Jr, Bus, J. S., Popp, J. A., Boreiko, C. J. \& Andjelkovich, D. A. (1984). A critical review of the literature on hydrogen sulfide toxicity. CRC Crit Rev Toxicol 13, 25-97.

Biebl, H. \& Pfennig, N. (1977). Growth of sulfate-reducing bacteria with sulfur as electron acceptor. Arch Microbiol 112, 453-455.

Brown, L. J. \& Löe, H. (1993). Prevalence, extent, severity and progression of periodontal disease. Periodontol 2000 2, 57-71.

Canfield, D. E. \& Des Marais, D. J. (1991). Aerobic sulfate reduction in microbial mats. Science 251, 1471-1473.

Devereux, R., He, S.-H., Doyle, C. L., Orkland, S., Stahl, D. A., LeGall, J. \& Whitman, W. B. (1990). Diversity and origin of Desulfovibrio species: phylogenetic definition of a family. $J$ Bacteriol 172, 3609-3619.

Dzierzewicz, Z., Cwalina, B., Kurkiewicz, S., Chodurek, E.. \& Wilczok, T. (1996). Intraspecies variability of cellular fatty acids among soil and intestinal strains of Desulfovibrio desulfuricans. Appl Environ Microbiol 62, 3360-3365. 
Edlund, A., Nichols, P. D., Roffey, R. \& White, D. C. (1985). Extractable and lipopolysaccharide fatty acid and hydroxy acid profiles from Desulfovibrio species. J Lipid Res 26, 982-988.

Gibson, G. R., Macfarlane, G. T. \& Cummings, J. H. (1988). Occurrence of sulphate-reducing bacteria in human faeces and the relationship of dissimilatory sulphate reduction to methanogenesis in the large gut. J Appl Bacteriol 65, 103-111.

Gibson, G. R., Cummings, J. H. \& Macfarlane, G. T. (1991). Growth and activities of sulphate-reducing bacteria in gut contents of healthy subjects and patients with ulcerative colitis. FEMS Microbiol Ecol 86, 103-112.

Haffajee, A. D. \& Socransky, S. S. (1994). Microbial etiological agents of destructive periodontal diseases. Periodontol $2000 \mathbf{5}$, 78-111.

Hansen, T. A. (1993). Carbon metabolism of sulfate-reducing bacteria. In The Sulfate Reducing Bacteria: Contemporary Perspectives, pp. 21-40. Edited by J. M. Odom \& R. Singleton, Jr. New York: Springer.

van der Hoeven, J. S., van den Kieboom, C. W. A. \& Schaeken, M. J. M. (1995). Sulfate-reducing bacteria in the periodontal pocket. Oral Microbiol Immunol 10, 288-290.

Jukes, T. H. \& Cantor, C. R. (1969). Evolution of protein molecules. In Mammalian Protein Metabolism, pp. 21-132. Edited by H. N. Munro. New York: Academic Press.

Kohring, L. L., Ringelberg, D. B., Devereux, R., Stahl, D. A., Mittelman, M. W. \& White, D. C. (1994). Comparison of phylogenetic relationships based on phospholipid fatty acid profiles and ribosomal RNA sequence similarities among dissimilatory sulfate-reducing bacteria. FEMS Microbiol Lett 119, 303-308.

Krumholz, L. R., Harris, S. H., Tay, S. T. \& Suflita, J. M. (1999). Characterization of two subsurface $\mathrm{H}_{2}$-utilizing bacteria, Desulfomicrobium hypogeium sp. nov. and Acetobacterium psammolithicum sp. nov., and their ecological roles. Appl Environ Microbiol 65, 2300-2306.

Laanbroek, H. J. \& Pfennig, N. (1981). Oxidation of short-chain fatty acids by sulfate-reducing bacteria in freshwater and in marine sediments. Arch Microbiol 128, 330-335.

Laanbroek, H. J., Geerligs, H. J., Sijtsma, L. \& Veldkamp, H. (1984). Competition for sulfate and ethanol among Desulfobacter, Desulfobulbus, and Desulfovibrio species isolated from intertidal sediments. Appl Environ Microbiol 47, 329-334.

Lane, D. J. (1991). 16S/23S rRNA sequencing. In Nucleic Acid Techniques in Bacterial Systematics, pp. 115-175. Edited by E. Stackebrandt \& E. Goodfellow. Chichester: Wiley.

Langendijk, P. S., Hagemann, J. \& van der Hoeven, J. S. (1999). Sulfate-reducing bacteria in periodontal pockets and in healthy oral sites. J Clin Periodontol 26, 596-599.

Langendijk, P. S., Hanssen, J. T. J. \& van der Hoeven, J. S. (2000). Sulfate-reducing bacteria in association with human periodontitis. J Clin Periodontol 27, 943-950.

La Scola, B. \& Raoult, D. (1999). Third human isolate of a Desulfovibrio sp. identical to the provisionally named Desulfovibrio fairfieldensis. J Clin Microbiol 37, 3076-3077.

Lee, J.-P., Yi, C.-S., LeGall, J. \& Peck, H. D., Jr (1973). Isolation of a new pigment, desulforubidin, from Desulfovibrio desulfuricans (Norway strain) and its role in sulfite reduction. J Bacteriol 115, 453-455.

Lin, C., Raskin, L. \& Stahl, D. A. (1997). Microbial community structure in gastrointestinal tracts of domestic animals: comparative analyses using rRNA-targeted oligonucleotide probes. FEMS Microbiol Ecol 22, 281-294.

Loubinoux, J., Mory, F., Pereira, I. A. C. \& Le Faou, A. E. (2000).
Bacteremia caused by a strain of Desulfovibrio related to the provisionally named Desulfovibrio fairfieldensis. $J$ Clin Microbiol 38, 931-934.

McDougall, R., Robson, J., Paterson, D. \& Tee, W. (1997). Bacteremia caused by a recently described novel Desulfovibrio species. J Clin Microbiol 35, 1805-1808.

Maidak, B. L., Cole, J. R., Parker, C. T., Jr \& 11 other authors (1999). A new version of the RDP (Ribosomal Database Project). Nucleic Acids Res 27, 171-173.

Mesbah, M., Premachandran, U. \& Whitman, W. B. (1989). Precise measurement of the $\mathrm{G}+\mathrm{C}$ content of deoxyribonucleic acid by high-performance liquid chromatography. Int $J$ Syst Bacteriol 39, 159-167.

Moore, W. E. \& Moore, L. V. (1994). The bacteria of periodontal diseases. Periodontol 2000 5, 66-77.

Okabe, S., Itoh, T., Satoh, H. \& Watanabe, Y. (1999). Analyses of spatial distributions of sulfate-reducing bacteria and their activity in aerobic wastewater biofilms. Appl Environ Microbiol 65, 5107-5116.

Pedersen, K., Arlinger, J., Ekendahl, S. \& Hallbeck, L. (1996). 16S rRNA gene diversity of attached and unattached bacteria in boreholes along the access tunnel to the Äspö hard rock laboratory, Sweden. FEMS Microbiol Ecol 19, 249-262.

Postgate, J. R. (1984). The Sulphate-reducing Bacteria, 2nd edn. Cambridge: Cambridge University Press.

Relman, D. A. (1993). Universal bacterial 16S rDNA amplification and sequencing. In Diagnostic Molecular Microbiology. Principles and Applications, pp. 489-495. Edited by D. H. Persing, T. F. Smith, F. C. Tenover \& T. J. White. Washington, DC: American Society for Microbiology.

Rozanova, E. P. \& Nazina, T. N. (1976). A mesophilic, sulfatereducing, rod shaped, nonsporeforming bacterium. Microbiology (English translation of Mikrobiologiya) 45, 711-716.

Rozanova, E. P., Nazina, T. N. \& Galushko, A. S. (1988). Isolation of a new genus of sulfate-reducing bacteria and description of a new species of this genus, Desulfomicrobium apsheronum gen. nov., sp. nov. Microbiology (English translation of Mikrobiologiya) 57, 514-520.

Sambrook, J., Fritsch, E. F. \& Maniatis, T. (1989). Molecular Cloning: a Laboratory Manual, 2nd edn. Cold Spring Harbor, NY : Cold Spring Harbor Laboratory.

Santegoeds, C. M., Ferdelman, T. G., Muyzer, G. \& de Beer, D. (1998). Structural and functional dynamics of sulfate-reducing populations in bacterial biofilms. Appl Environ Microbiol 64, 3731-3739.

Sharak Genthner, B. R., Mundfrom, G. \& Devereux, R. (1994). Characterization of Desulfomicrobium escambium sp. nov. and proposal to assign Desulfovibrio desulfuricans Norway 4 to the genus Desulfomicrobium. Arch Microbiol 161, 215-219.

Sharak Genthner, B. R., Friedman, S. D. \& Devereux, R. (1997). Reclassification of Desulfovibrio desulfuricans Norway 4 as Desulfomicrobium norvegicum comb. nov. and confirmation of Desulfomicrobium escambiense (corrig., formerly "escambium") as a new species in the genus Desulfomicrobium. Int J Syst Bacteriol 47, 889-892.

Smith, L. (1978). Bacterial cytochromes and their spectral characterization. Methods Enzymol 53, 202-212.

Socransky, S. S. \& Haffajee, A. D. (1997). The nature of periodontal diseases. Ann Periodontol 2, 3-10.

Swofford, D. L. (1998). PAUP*. Phylogenetic analysis using parsimony (*and other methods), version 4. Sunderland, MA: Sinauer Associates. 
Taylor, J. \& Parkes, R. J. (1983). The cellular fatty acids of the sulphate-reducing bacteria, Desulfobacter sp., Desulfobulbus sp. and Desulfovibrio desulfuricans. J Gen Microbiol 129, 3303-3309.

Tee, W., Dyall-Smith, M., Woods, W. \& Eisen, D. (1996). Probable new species of Desulfovibrio isolated from a pyogenic liver abscess. J Clin Microbiol 34, 1760-1764.

Tourova, T. P., Nazina, T. N., Poltaraus, A. B. \& Osipov, G. A. (1998). Phylogenetic position and chemotaxonomic characteristics of sulfate-reducing bacteria of the genus Desulfomicrobium. Microbiology (English translation of Mikrobiologiya) 67, 663-669.

Vainshtein, M., Hippe, H. \& Kroppenstedt, R. M. (1992). Cellular fatty acid composition of Desulfovibrio species and its use in classification of sulfate-reducing bacteria. Syst Appl Microbiol 15, 554-566.

Widdel, F. (1988). Microbiology and ecology of sulfate- and sulfur-reducing bacteria. In Biology of Anaerobic Microorganisms, pp. 469-585. Edited by A. B. J. Zehnder. New York: Wiley.

Willis, C. L., Gibson, G. R., Allison, C., Macfarlane, S. \& Holt, J. S. (1995). Growth, incidence and activities of dissimilatory sulfatereducing bacteria in the human oral cavity. FEMS Microbiol Lett 129, 267-271.

Willis, C. L., Gibson, G. R., Holt, J. \& Allison, C. (1999). Negative correlation between oral malodour and numbers and activities of sulphate-reducing bacteria in the human mouth. Arch Oral Biol 44, 665-670. 